\title{
Labour unionisation structure and product innovation ${ }^{\dagger}$
}

\author{
Debasmita Basak \\ Nottingham University Business School, UK \\ Arijit Mukherjee \\ Nottingham University Business School, UK, CESifo, Germany, INFER, Germany, \\ and GRU, City University of Hong Kong, Hong Kong
}

December 2017

\begin{abstract}
This paper contributes to the recently growing literature by examining the effects of different labour unionisation structures on innovation. Using a Cournot duopoly set up, we investigate the effects of centralised and decentralised labour unions on product innovation. We show that if the products are symmetrically differentiated, the incentive for innovation is higher under decentralised labour unions, whereas the innovation incentive can be higher under a centralised labour union if the products are asymmetrically differentiated. Our results show that social welfare is strictly higher under decentralised unions compared to a centralised union.
\end{abstract}

Keywords: Centralised union; Decentralised union; Product innovation; Union utility

JEL Classification: D43; J51; L13; O31

Correspondence to: Debasmita Basak

Nottingham University Business School, Jubilee Campus,

Wollaton Road, Nottingham, NG8 1BB, UK

Email: debasmita.basak@nottingham.ac.uk, Phone: +44 115748 4090, Fax: +44 1158466667.

\footnotetext{
${ }^{\dagger}$ We appreciate the comments received from two anonymous referees which helped to improve the quality of the paper. We thank all seminar participants at University of Nottingham and conference participants of Annual Conference of Scottish Economic Society. We also thank Bouwe Dijkstra for insightful comments and suggestions. The usual disclaimer applies.
} 


\section{Introduction}

The purpose of this paper is to analyse the effects of different labour unionisation structures on the firms' incentives to innovate new products.

Labour unions differ substantially between countries with respect to the degree of wage setting centralisation (Calmfors and Driffill, 1988; Moene and Wallerstein, 1997; Flanagan, 1999 and Wallerstein, 1999). Decentralised wage setting is often contrasted with centralised wage setting. Under a decentralised wage setting, wages are set between employers and firm-specific unions, while under a centralised wage setting, an industry-wide union negotiates wages with all firms (Haucap and Wey, 2004). While the centralised argument is egalitarian in nature and generally makes the sufficiently substitutable workers better off (Horn and Wolinsky, 1988 and Davidson, 1988), the rigidity associated with this system is generally bad for overall economic performance (Nickell, 1997 and Siebert, 1997).

Given the diversity of unionised labour market, there is a growing literature (Haucap and Wey, 2004; Calabuig and Gonzalez-Maestre, 2002; Manasakis and Petrakis, 2009; Mukherjee and Pennings, 2011) that investigates the effects of different labour unionisation structures on innovation. Although the existing literature provides several important insights, their focus remained only on process innovation. Investment in process innovation is certainly a major part of firms' $R \& D$ expenditure, however, the firms in today's world also allocate a significant amount of their R\&D budget towards product innovation. For example, as mentioned in Imai (1992), the Japanese firms allocate $R \& D$ budget in process innovation relative to product innovation at a ratio of 60:40. It is argued in Mansfield (1988) that American firms have traditionally spent more in product innovation than Japanese firms. Our paper aims at closing the gap between product innovation and the structures of labour unions. 
It is intuitive that process and product innovations create different effects on labour demand and unionised wage. While product innovation increases the number of products in the market, by creating new demand for workers; process innovation, on the other hand, reduces the number of workers required in the production process by lowering the demand for workers. Hence, the effects of unionisation structures on product innovation demand new analysis. We take up this issue in this paper. Following the existing literature alluded earlier, we compare the incentives for innovation under a centralised union and decentralised unions respectively. ${ }^{1}$

The main contribution of our paper lies in its focus on new product development, thus affecting the number of products offered in the market. This is in contrast to the existing literature that defines product innovation as an outcome of superior product quality or new process development of the existing products, thus keeping the number of products unaltered in the market. Symeonidis (2003) argue that an improvement in product quality can be interpreted as product innovation. Lin and Saggi (2002), Rosenkranz (2003), Braun (2008) and Lambertini and Mantovani (2009, 2010), on the other hand, investigate the effects of product innovation where the degree of product substitutability acts as a proxy of product R\&D. We depart from this strand of literature by considering the aspect of new product development which is marketed in addition to the existing products. Our modelling of product innovation is easily justifiable within multinational technology intensive firms. For example, Apple sells iPad in addition to MacBook, Samsung sells Galaxy Tab in addition to notebook.

We develop a simple model of product innovation in Section 2. In a duopoly market structure, we assume that each firm has an existing product and may become a

\footnotetext{
1 Although we consider labour union as an upstream agent, it is worth mentioning that our results will hold if instead of labour unions, we portray the upstream agents as profit maximising input suppliers. With this interpretation, decentralised bargaining corresponds to a situation where firm-specific input suppliers bargain with the respective firms, and the centralised bargaining corresponds to a situation where a representative of the input suppliers bargains with a representative of the final goods producers.
} 
multiproduct firm by innovating a new product. We begin our analysis with the case where the products are symmetrically differentiated. A comparison between centralised and decentralised unions reveals that the latter union structure provides higher incentive for innovation compared to the former union structure.

Although symmetric product differentiation can be a useful starting point, it may be a strong assumption to consider, particularly, if this assumption is important for our results. We show in Section 3 that the innovation incentive can be higher under a centralised union than under decentralised unions when the products are asymmetrically differentiated. In this section, we assume that the existing products are perfect substitutes and the new products are different from the existing products. This structure is certainly justifiable. As an example, we may visualise the first generation mobile phones which are mainly used for making calls and sending text messages as the existing products of the firms; whereas the third generation mobile phones with added features, such as better screen size, superior graphics, improved camera quality and web browsing facility, can be regarded as the imperfect substitutes of the existing products. One may argue that the first generation mobile phones can also be interpreted as imperfect substitutes due to their different layouts and the longevity of battery lives, however, it is more natural to assume that the third generation mobile phones are imperfect substitutes of the first generation mobile phones. As a simplification, we presume the first generation phones as perfect substitutes.

With this setup our results show that the incentive for product innovation is higher under decentralised unions compared a centralised union if the existing and the new products are sufficiently differentiated meaning that the existing products do not face much competition from the new products. And, the result is reversed if the degree of product differentiation between the existing and the new products is sufficiently low. Further, we find that decentralised unions are welfare improving compared to a 
centralised union irrespective of the type of product differentiation.

As discussed earlier, there is a strand of literature on innovation and unions that largely considers the effects of unions on process innovation and productivity. In a patent race model, Haucap and Wey (2004) show that if a centralised labour union charges a uniform wage to all firms, the incentive for innovation is higher under a centralised labour union. However, in case of wage discrimination by the centralised labour union, the incentive for innovation is higher under decentralised labour unions. In a model with R\&D competition, Calabuig and Gonzalez-Maestre (2002) show that the incentive for innovation is higher under decentralised labour unions for non-drastic innovations, while the incentive for innovation can be higher under a centralised labour union when the innovation is drastic in nature. Manasakis and Petrakis (2009) show that, under non-cooperative $\mathrm{R} \& \mathrm{D}$, the incentive for innovation is higher under decentralised labour unions if knowledge spillovers are high, but the incentive for innovation is always higher under decentralised labour unions under cooperative R\&D. Considering an innovating firm and a non-innovating firm, Mukherjee and Pennings (2011) show the implications of technology licensing ex-post innovation. They show that if the unions' preferences for wage (compared to employment) are high, the innovator's incentive for innovation is higher under a centralised labour union irrespective of licensing ex-post innovation. However, if the unions' preferences for employment are high, the benefit from licensing may help to create higher incentive for innovation under decentralised labour unions. ${ }^{2}$

The reasons behind the above-mentioned results are related to different types of constraints imposed by different union structures. Haucap and Wey (2004) show that the uniformity rule under a centralised union is more effective in constraining the

\footnotetext{
2 In contrast to these papers, earlier works have shown the impacts of union bargaining power. See Grout (1984) and Van der Ploeg (1987) for surveys and Tauman and Weiss (1987) and Ulph and Ulph (1994 and 2001) for more recent contributions in this strand of literature.
} 
unions' hold-up potential that leads to higher incentives for innovation under a centralised union. However, if the centralised union discriminates wage, it helps the union to exploit its hold-up problem at the fullest, and as a result the innovation incentive can be lower under a centralised union. Calabuig and Gonzalez-Maestre (2002) show that the hold-up problems are affected by the nature of innovation, which may make production by the non-innovating firm unprofitable. Manasakis and Petrakis (2009) show that the degree of knowledge spillover and cooperation in R\&D affect the hold-up problems created by the unionisation structures. In Mukherjee and Pennings (2010), the hold-up problems are present both in the innovation stage and in the technology licensing stage. Under licensing ex-post innovation, competition between the unions under decentralised unions is more effective in softening the hold-up problem, thus creating a stronger incentive for licensing under decentralised unions.

In contrast, product innovation creates different wage effects in our analysis. If a firm invents a new product, its labour demand increases due to an increase in the number of products produced by the innovator, although the new product reduces labour demand for the existing products. Whether this wage effect increases the hold-up problem under decentralised unions or under a centralised union depends on the degree of product differentiation between the existing and the new products. In contrast to the previous papers on process innovation, in our paper, the labour unionisation structures may have ambiguous effects on product innovation even if the centralised union charges a uniform wage, the innovations are non-drastic and there is neither knowledge spillover nor technology licensing.

So far, we have focused on the theoretical literature showing the effects of labour unions on innovation. There is also an empirical literature showing the relationship between labour unions and innovation. The level of wage bargaining, the bargaining agenda and the bargaining power distribution between the firms and the 
unions are among the important determinants of innovation (Bassanini and Ernst, 2002 and Hirsch, 2004), yet there is controversy about their exact effects on firms' performance, innovation and labour productivity (see, Flanagan, 1999, for a survey on this topic). The existing empirical works showing the effects of union on innovation mainly show the effects of union power on the incentives for innovation. Freeman and Medoff (1984) show that the effect of unionisation is ambiguous on innovation. Using COMPUSTAT data, Bronas and Deere (1993) show that there is a significant negative relationship between firm-specific unionisation rate and innovation. Using mainly aggregative industry level data, Ulph and Ulph (1989) find a negative relation for the high-tech industries in England, while Addison and Wagner (1994) find a positive but insignificant relation. It is documented in Menezes-Filho et al. (1998) that most U.S. studies show a negative effect between union power and innovation, while the evidence from some European studies is less compelling. ${ }^{3}$ Menezes-Filho and Van Reenen (2003) also show strong and negative effects of unions on innovation in North America, while that is generally not the case in the UK.

Our results can also be related to the literature that shows the effects of unions on innovation in general equilibrium growth models. Palokangas (1996) considers an economy where innovation requires only skilled labour, and the union-employer federation bargains for skilled and unskilled wages. In this framework, the paper shows that higher wages for unskilled workers boost innovation. Using a two-sector model where a high-tech sector innovates in the presence of union-firm bargaining and a traditional sector where there is no innovation and no labour union, Palokangas (2004) shows that an increase in union power increases innovation. Chu et al. (2016) show that an increase in union power creates a positive effect on innovation under an

\footnotetext{
${ }^{3}$ In the European Union centralised unionisation is generally more common, while decentralised unionisation is more relevant in the U.S. See Iversen (1998) for an index of centralisation of wage bargaining in different countries.
} 
employment-oriented union, a negative effect on innovation under a wage-oriented union, and a neutral effect on innovation if the union is neither wage nor employment oriented. The wage raising effect in this strand of literature relates closely to the centralised union structure in our model. In line with the empirical evidences showing ambiguous effects of stronger unions on innovation, our results show that whether a centralised labour union, which is considered to be a stronger form of union than decentralised labour unions, reduces the incentive for innovation can be justified by the degree of product differentiation. Our paper provides testable hypotheses for future empirical works.

The remainder of the paper is organised as follows. In section 2, we describe the model and derive the results under symmetrically differentiated products. Section 3 shows the implications of asymmetric product differentiation. Section 4 concludes.

\section{The implications of symmetric product differentiation}

We consider an economy where two firms, denoted by $k=1,2$ compete in quantities. We assume that initially firm 1 and firm 2 produce goods $g$ and $h$ respectively that are horizontally differentiated. Further, each firm may innovate a new product by investing $I>0$. We denote the new products of firms 1 and 2 by $y$ and $z$ respectively. The R\&D process in our work follows the model of Calabuig and Gonzalez-Maestre (2002), Haucap and Wey (2004) and Mukherjee and Pennings (2011) with the exception that, instead of assuming that $R \& D$ reduces the cost of production, our focus remains on new product development. Our modelling of product innovation is in line with Mukherjee and Sinha (2012).

We assume that labour, $L_{i}$, is the only factor of production where $i$ indexes the goods produced in the economy. The total labour demand per firm becomes 
$L_{k}=\sum_{i} L_{i}$. We assume that the production process exhibits constant returns to scale, meaning that each firm requires one worker to produce one unit of output. We depart from the analysis of heterogeneity in labour productivity as we want to study the effects of product innovation in isolation. The wages of the workers are endogenous and are determined by labour unions. In order to capture the maximum effect of unions' wage setting behaviour, following Calabuig and Gonzalez-Maestre (2002) and Haucap and Wey (2004), we assume that the labour unions have full bargaining power over wage determination whereas the levels of employment and output are set by the firms subsequently. ${ }^{4}$ To avoid unnecessary complications and to have better insights on the hold-up problem, following Ulph and Ulph (1989, 1994, 1998), we assume that labour unions are unable to commit to wages before $\mathrm{R} \& \mathrm{D} .^{5}$

Assume that the inverse market demand function of the $i^{t h}$ product is given by

$$
P_{i}=a-q_{i}-\gamma \sum_{j} q_{j}
$$

where, $i, j=\{g, h, y, z\}, i \neq j, \quad P_{i}$ and $q_{i}$ denote the price and output of product $i$ respectively. The parameter $\gamma \in[0,1]$ measures the degree of product differentiation.

\footnotetext{
${ }^{4}$ This type of wage determination is in line with the right-to-manage model of labour union. The wage determination, however, could take the form of efficient bargaining where the labour unions and the firms bargain over the wage rate and employment level simultaneously. The right-to-manage model gained more popularity in the policy circle compared to the efficient bargaining model because it is difficult to prescribe a contract which constitute an efficient combination of wages and employment. As reported by Oswald (1993), in response to his questionnaire: "Does your union normally negotiate over the number of jobs as well as over wages and condition?" only two US respondents (out of 19) and only three British respondents (out of 18) answered assertive. Layard et al. (1991) also offered some arguments in favour of this issue. He mentioned that bargaining does not generally takes place over employment simply because the existing workers only care about their own job securities rather than paying much attention to the employment level of the firms. In light of this argument, we adopt a right-to-manage model for our analysis.

5 In line with the cited literature we cast the analysis in a short-term bargaining context where union-firm bargaining does not involve R\&D investment. It should be noted though there are real problems of long-term bargaining where the labour unions may bargain over firm's R\&D effort, product variety alongside wage. Incorporating such elements in the analysis lies outside the scope of the present paper but is left as a topic for future research.
} 
If $\gamma=1$, the products are perfect substitutes and if $\gamma=0$, the products are isolated. Since we consider products $y$ and $z$ to be different from products $g$ and $h$, we restrict our analysis to $\gamma \in[0,1)$.

We consider the following game structure. At stage 1, the firms decide simultaneously whether to market a new product. At stage 2, the wages are determined by labour unions. To this extent we consider two different types of unionisation structures - a centralised union and decentralised unions - which we index by $\rho=\{c, d\}$. Finally, at stage 3 , the firms compete like Cournot duopolists and the profits are realised. We solve the game through backward induction.

\subsection{The equilibrium outputs}

We start by considering the output game. At this stage, the firms take the number of products and the wages as given.

First, consider the case where neither firm innovates a new product. If firm 1 and 2 produce goods $g$ and $h$ respectively and if the wages paid by firm 1 and 2 are $w_{1}$ and $w_{2}$, the respective equilibrium outputs are:

$$
\begin{aligned}
& \hat{q}_{g}^{\rho}=\frac{(2-\gamma) a-2 w_{1}^{\rho}+\gamma w_{2}^{\rho}}{4-\gamma^{2}} \\
& \hat{q}_{h}^{\rho}=\frac{(2-\gamma) a+\gamma w_{1}^{\rho}-2 w_{2}^{\rho}}{4-\gamma^{2}}
\end{aligned}
$$

Now consider the case where only firm 1 innovates the new product. In this situation, firm 1 produces $g$ and $y$ and firm 2 produces $h$. We get the resulting equilibrium outputs as:

$$
\begin{aligned}
& \tilde{q}_{g}^{\rho}=\tilde{q}_{x}^{\rho}=\frac{(2-\gamma) a-2 w_{1}^{\rho}+\gamma w_{2}^{\rho}}{2\left(2+2 \gamma-\gamma^{2}\right)} \\
& \tilde{q}_{h}^{\rho}=\frac{a+\gamma w_{1}^{\rho}+(1-\gamma) w_{2}^{\rho}}{2\left(2+2 \gamma-\gamma^{2}\right)}
\end{aligned}
$$


Similarly, if only firm 2 invests in innovating the new product, firm 1 produces $g$ and firm 2 produces $h$ and $z$. The resulting equilibrium outputs become:

$$
\begin{aligned}
& \tilde{q}_{g}^{\rho}=\frac{a+\gamma w_{1}^{\rho}+(1-\gamma) w_{2}^{\rho}}{2\left(2+2 \gamma-\gamma^{2}\right)} \\
& \tilde{q}_{h}^{\rho}=\tilde{q}_{z}^{\rho}=\frac{(2-\gamma) a-2 w_{1}^{\rho}+\gamma w_{2}^{\rho}}{\left(2+2 \gamma-\gamma^{2}\right)}
\end{aligned}
$$

Finally, consider the case where both firms innovate new products. In this situation, firm 1 produces $g$ and $y$ and firm 2 produces $h$ and $z$. We get the outputs as:

$$
\begin{aligned}
& \bar{q}_{g}^{\rho}=\bar{q}_{x}^{\rho}=\frac{a-(1+\gamma) w_{1}^{\rho}+\gamma w_{2}^{\rho}}{(1+2 \gamma)} \\
& \bar{q}_{h}^{\rho}=\bar{q}_{y}^{\rho}=\frac{a+\gamma w_{1}^{\rho}-(1+\gamma) w_{2}^{\rho}}{2(1+2 \gamma)}
\end{aligned}
$$

\subsection{Wages and profits}

Having derived the equilibrium output levels in Section 2.1, we now determine the equilibrium wages under the respective union structures conditional on firms' innovation strategies.

\subsubsection{A centralised union}

We start our analysis where the wages are set by a centralised labour union. Under such union structure we assume two types of wage setting behaviour of the labour union - uniform wage setting and discriminatory wage setting. The industry-wide union maximises the utility function $U=(w-c) \sum L_{k}$ with respect to wage, $w$, in the former case, whereas it maximises $U=\sum\left(w_{k}-c\right) L_{k} ; \quad k=1,2$ with respect to wage, $w_{k}$, in the latter case. We denote the reservation wage of the workers by $c \in(0, a)$. 
We get the equilibrium wage as $w^{c}=\frac{1}{2}(a+c)$ regardless of the wage setting behaviour of the labour union. The rationale for this result follows from Dhillon and Petrakis (2002), who show that, when the union structure is centralised in nature, and firms' equilibrium outputs and profits are log-linear in input prices and market features such as the number of firms and product differentiation; the equilibrium input price remain the same irrespective of the degree of product differentiation and type of the product market competition.

Given the centralised structure of the labour union, we now turn our analysis to stage 1 where the firms determine their investment levels towards innovation. On this note, we report each firm's realised profits in Table 1 under the respective innovation strategies. Let $\pi_{k}^{c}[.,$.$] , in Table 1$ denote the profit of the $k^{\text {th }}$ firm, $k=1,2$, where the first (second) argument shows the goods produced by firm 1 (firm 2). For example, $\pi_{k}^{c}[(g, y), h]$ shows the profit of the $k^{\text {th }}$ firm when firm 1 innovates and produces goods $g$ and $y$ whereas firm 2 does not innovate and produces good $h$ only.

Table 1: Firms' pay-offs under a centralised union

\begin{tabular}{|c|c|c|}
\hline Firm 2 & R\&D & No R\&D \\
\hline R\&D & $\pi_{1}^{c}[(g, y) ;(h, z)]-I$, & $\pi_{1}^{c}[(g, y) ; h]-I$, \\
& $\pi_{2}^{c}[(g, y) ;(h, z)]-I$ & $\pi_{2}^{c}[(g, y) ; h]$ \\
\hline No R\&D & $\pi_{1}^{c}[g ;(h, z)]$, & $\pi_{1}^{c}[g ; h]$, \\
& $\pi_{2}^{c}[g ;(h, z)]-I$ & $\pi_{2}^{c}[g ; h]$ \\
\hline
\end{tabular}


The closed form solutions of the profits are documented in Table A.1 in Appendix A.

From Table 1 we derive the Nash equilibria of the innovation game for different investment costs. The incentive for a firm to innovate, given the strategy of its competitor is the difference in profits between innovation and no innovation. In the following proposition, we define the investment costs at which no firm innovates, both firms innovate and only one firm innovates. Accordingly, which Nash equilibrium is achieved depends on the size of the cost of innovation, $I$.

Proposition 1: Assume that the labour union is centralised in nature.

(a) Both firms innovate if $I<I_{l}^{c}$,

(b) Neither firm innovates if $I_{h}^{c}<I$,

(c) Only one firm innovates if $I_{l}^{c}<I<I_{h}^{c}$

where, $I_{l}^{c}=\frac{(a-c)^{2}(1-\gamma)\left(2+6 \gamma+6 \gamma^{2}+2 \gamma^{3}-\gamma^{4}\right)}{8(1+2 \gamma)^{2}\left(2+2 \gamma-\gamma^{2}\right)^{2}}$

and, $I_{h}^{c}=\frac{(a-c)^{2}(1-\gamma)\left(8+8 \gamma-\gamma^{4}\right)}{8(2+\gamma)^{2}\left(2+2 \gamma-\gamma^{2}\right)^{2}}$.

Proof: Check that $I_{l}^{c}-I_{h}^{c}=-\frac{\gamma(1+\gamma)(a-c)^{2}(1-\gamma)^{2}\left(8+14 \gamma+2 \gamma^{2}+3 \gamma^{3}\right)}{8(2+\gamma)^{2}(1+2 \gamma)^{2}\left(2+2 \gamma-\gamma^{2}\right)^{2}}<0$.

If $I<I_{l}^{c}$, both firms innovate, and we denote this equilibrium by (RD, RD). If $I>I_{h}^{c}$, neither firm innovates, and we denote this equilibrium by (No RD, No RD). If $I_{l}^{c}<I<I_{h}^{c}$, only one firm innovates, and we name these equilibria by (RD, No RD) and (No RD, RD). 
The incentive for innovation is driven by two effects - strategic benefit and non-strategic benefit of innovation (Roy Chowdhury, 2005). A firm's non-strategic benefit, $I_{h}^{c}$ (strategic benefit, $I_{l}^{c}$ ) from innovation is given by its payoff from innovation, net of its payoff from no innovation, when the competitor firm does not innovate (innovates). ${ }^{6}$ Formally, we define firm 1's non-strategic and strategic benefits by $I_{l}^{\rho} \leq \pi_{1}^{\rho}[(g, y) ;(h, z)]-\pi_{1}^{\rho}[g ;(h, z)] \quad$ and $\quad I_{h}^{\rho} \leq \pi_{1}^{\rho}[g ; h]-\pi_{1}^{\rho}[(g, y) ; h]$ respectively. Therefore, firm 1 does not innovate if its gross non-strategic benefit from innovation is less than the cost of innovation, i.e., $I_{h}^{c}<I$ and firm 1 innovates if its gross strategic benefit from innovation is greater than the cost of innovation, i.e., $I<I_{l}^{c}$. Since the firms are symmetric, similar arguments hold for the rival firm. ${ }^{7}$ Proposition 1 shows that the non-strategic benefit from innovation is higher than the strategic benefit from innovation, i.e., $I_{l}^{c}<I_{h}^{c}$.

Let us illustrate this further. Innovation creates two opposing effects on the profitability of the innovator. On the one hand, it tends to increase the profit of the innovating firm by allowing it to add variety to its products. On the other hand, the cost of innovation tends to reduce the profit of the innovator. If the cost of innovation is significantly small, i.e., $I<I_{l}^{c}$, the first effect dominates the second effect, and both firms find innovation profitable. On the other extreme, if the cost of innovation is very high, i.e., $I_{h}^{c}<I$, the second effect dominates the first effect, and neither firm finds innovation profitable. If the cost of innovation is moderate, i.e., $I_{l}^{c}<I<I_{h}^{c}$, a firm

\footnotetext{
${ }^{6}$ There is also a mixed strategy equilibrium where the firms randomise on innovation and no innovation. However, we focus only on the pure strategy equilibria in this paper.

${ }^{7}$ In the terminology of Ulph and Ulph (1998), the critical values $I_{l}^{\rho}$ and $I_{h}^{\rho}$ represent "competitive threats", which is the difference between a firm's profits if it innovates and the profits if it does not innovate, given the strategy of its rival firm.
} 
finds innovation profitable if the other firm does not innovate so that the innovator's gain from the new product is sufficiently large to cover the cost of innovation.

\subsubsection{Decentralised union}

Now, consider the scenario where the wages are set by the decentralised unions. The firm-specific union maximises the utility function $U_{k}=\left(w_{k}-c\right) L_{k}$ with respect to $w_{k}$ where $k=1,2$.

We summarise the equilibrium wages under four different constellations. If neither firm innovates, the equilibrium wages ex-post $R \& D$ are:

$$
\hat{w}_{1}^{d}=\hat{w}_{2}^{d}=\frac{a(2-\gamma)+2 c}{4-\gamma}
$$

Next, we consider the case where only one firm innovates. For notational ease, we denote the innovating firm by ' $i v$ ' and the non-innovating firm by ' $n v$ '. In this case, the equilibrium wages give:

$$
\begin{aligned}
& \tilde{w}_{i v}^{d}=\frac{a\left(4+3 \gamma-2 \gamma^{2}\right)+c(1+\gamma)(4+\gamma)}{\left(8+8 \gamma-\gamma^{2}\right)} \\
& \tilde{w}_{n v}^{d}=\frac{a\left(4+2 \gamma-\gamma^{2}\right)+2 c(2+3 \gamma)}{8+8 \gamma-\gamma^{2}}
\end{aligned}
$$

Finally, if both firms innovate, the equilibrium wages yield:

$$
\bar{w}_{1}^{d}=\bar{w}_{1}^{d}=\frac{a+c(1+\gamma)}{2+\gamma} .
$$

The following lemma is immediate from the above discussion.

Lemma 1: Assume that the labour unions are decentralised in nature. We get the following wage rankings:

(a) Compared to the case with no innovation, innovation reduces the wage paid by the innovating firm when both firms innovate, i.e., $\bar{w}_{k}^{d}-\hat{w}_{k}^{d}<0$, and when only one 
firm innovates, i.e., $\tilde{w}_{i v}^{d}-\hat{w}_{k}^{d}<0$.

(b) The wage paid by the innovating firm is lower when both firms innovate compared to the case where only one firm innovates, i.e., $\bar{w}_{k}^{d}-\tilde{w}_{i v}^{d}<0$.

Proof: See that $\bar{w}_{k}^{d}-\hat{w}_{k}^{d}=-\frac{\gamma(a-c)(1-\gamma)}{(4-\gamma)(2+\gamma)}<0, \tilde{w}_{k}^{d}-\hat{w}_{k}^{d}=-\frac{\gamma^{2}(a-c)(1-\gamma)}{(4-\gamma)\left(8+8 \gamma-\gamma^{2}\right)}<0$ and $\bar{w}_{k}^{d}-\tilde{w}_{k}^{d}=-\frac{2 \gamma(a-c)\left(1-\gamma^{2}\right)}{(2+\gamma)\left(8+8 \gamma-\gamma^{2}\right)}<0$.

Lemma 1 states that innovation makes the innovating firm more cost efficient by lowering the wages paid to the labour union. The intuition goes as follows. Innovation (compared to no innovation) increases the labour demand of the innovating firm. As unions care about employment and wages, the outward shift of the labour demand curve leads to a new equilibrium at the more elastic part of the labour demand curve, which results in a reduction of the equilibrium wage paid by the innovating firm.

The second part of the lemma states that the firms become even more cost efficient when both firms innovate. The reason is that with both firms introducing new products to the market, the aggregate demand increases substantially, shifting the labour demand curve further out. The new equilibrium in the wage setting is on an even less elastic part of the labour demand curve, resulting in a lower wage.

Having derived the equilibrium wage rates, we now derive equilibrium profits of the firms conditional on innovation strategies. The following table summarises the equilibrium net profits of the firms under decentralised unions. 
Table 2: Firms' pay-offs under decentralised unions

\begin{tabular}{|c|c|c|}
\hline Firm 2 & R\&D & No R\&D \\
\hline R\&D 1 & $\pi_{1}^{d}[(g, y) ;(h, z)]-I$, & $\pi_{1}^{d}[(g, y) ; h]-I$, \\
& $\pi_{2}^{d}[(g, y) ;(h, z)]-I$ & $\pi_{2}^{d}[(g, y) ; h]$ \\
\hline No R\&D & $\pi_{1}^{d}[g ;(h, z)]$, & $\pi_{1}^{d}[g ; h]$, \\
& $\pi_{2}^{d}[g ;(h, z)]-I$ & $\pi_{2}^{d}[g ; h]$ \\
\hline
\end{tabular}

We report the closed form solutions of the profits in Table A.2 in Appendix A. Solving the above game analogous to the case of centralised union gives the following.

Proposition 2: Assume that the labour unions are decentralised in nature.

(a) Both firms innovate if $I<I_{l}^{d}$,

(b) Neither firm innovates if $I_{h}^{d}<I$,

(c) Only one firm innovates if $I_{l}^{d}<I<I_{h}^{d}$

where, $I_{l}^{d}=\frac{1}{2}(a-c)^{2}(1+\gamma)^{2}\left(\frac{1+\gamma}{(1+2 \gamma)^{2}(2+\gamma)^{2}}-\frac{2\left(4+2 \gamma-\gamma^{2}\right)^{2}}{\left(2+2 \gamma-\gamma^{2}\right)^{2}\left(8+8 \gamma-\gamma^{2}\right)^{2}}\right)$ and, $I_{h}^{d}=2(a-c)^{2}\left(\frac{(1+\gamma)\left(4+2 \gamma+\gamma-2 \gamma^{2}\right)^{2}}{\left(2+2 \gamma-\gamma^{2}\right)^{2}\left(8+8 \gamma-\gamma^{2}\right)^{2}}-\frac{2}{(2+\gamma)^{2}(4-\gamma)^{2}}\right)$.

Proof: Check that $I_{l}^{d}-I_{h}^{d}=-\frac{\gamma(a-c)^{2}(1-\gamma)^{2} \eta_{1}}{2(4-\gamma)^{2}(2+\gamma)^{2}(1+2 \gamma)^{2}\left(8+8 \gamma-\gamma^{2}\right)^{2}\left(2+2 \gamma-\gamma^{2}\right)^{2}}<0$ where 
$\eta_{1}=\left(1024+3968 \gamma+3840 \gamma^{2}-1680 \gamma^{3}-2880 \gamma^{4}+1056 \gamma^{5}+1216 \gamma^{6}-298 \gamma^{7}-120 \gamma^{8}+31 \gamma^{9}-\gamma^{10}\right)$.

Analogous to the case of centralised union, $I_{h}^{d}$ and $I_{l}^{d}$ denote a firm's non-strategic and strategic benefits from innovation respectively. The effects of innovation on a firm's profit, as discussed in Proposition 1, remain in Proposition 2.

\subsection{The effects of the unionisation structure on innovation}

Comparing the critical values mentioned in Propositions 1 and 2, we get the following investment ranking: ${ }^{8}$

$$
I_{l}^{c}<I_{h}^{c}<I_{l}^{d}<I_{h}^{d}
$$

for $\gamma \in[0,1)$. The above inequality suggests that, for a given cost of innovation, the number of firms investing in innovation cannot be lower under decentralised unions compared to a centralised union.

Hence, the following proposition is immediate.

Proposition 3: Decentralised unions provide higher incentive for innovation compared to a centralised labour union.

In contrast to decentralised unions, a centralised union internalises (indirect) competition between labour unions. The bargaining power being more monopolised under the industry-wide union, the hold-up problem and hence, the equilibrium wages are also higher under such union structure than decentralised unions. Clearly, a higher wage demand by the centralised union serves as a negative externality towards firm's innovation incentives. Therefore, the firms invest less under a centralised union than under decentralised unions.

\footnotetext{
${ }^{8}$ The proof of the investment ordering is documented in Appendix A.3.
} 


\subsection{Welfare analysis}

In this section, we discuss the social desirability of union intervention on firms' R\&D efforts under the two union structures. We define social welfare (SW) as the sum of consumer surplus (CS), producer surplus (PS) and union utilities (U). Due to the complexity of the mathematical expressions we restrict the welfare analysis to two polar cases across unions - the case where neither firm innovates and the situation where both firms innovate. We summarise the results below:

Lemma 2: Decentralised unions yield higher social welfare compared to a centralised union regardless of whether no firm innovates or both firms innovate.

Proof: See that $\widehat{S W}_{k}^{d}-\widehat{S W}_{k}^{c}=\frac{4(a-c)^{2}\left(7+\gamma-\gamma^{2}\right)}{(2+\gamma)^{2}(4-\gamma)^{2}}-\frac{(a-c)^{2}(7+3 \gamma)}{4(2+\gamma)^{2}}=\frac{\gamma(a-c)^{2}(3-\gamma)(8+3 \gamma)}{4(2+\gamma)^{2}(4-\gamma)^{2}}>$ 0 and $\overline{S W}_{k}^{d}-\overline{S W}_{k}^{c}=\frac{4(a-c)^{2}(1+\gamma)\left(7+16 \gamma+5 \gamma^{2}\right)}{2(1+2 \gamma)^{2}(2+\gamma)^{2}}-\frac{(a-c)^{2}(7+13 \gamma)}{8(1+2 \gamma)^{2}}=\frac{\gamma(a-c)^{2}(3+\gamma)(4+7 \gamma)}{8(1+2 \gamma)^{2}(2+\gamma)^{2}}>$ 0.

The above results reveal that the level of social welfare is higher under the decentralised unions compared to a centralised union. This result is driven by the wage effects across the union structures. We find that the equilibrium wages are strictly lower under decentralised unions compared to a centralised union regardless of whether neither firm invests or both firms invest in innovating new products. ${ }^{9}$ Clearly, a lower wage demand by the firm-specific unions generates higher producers surplus, higher consumers surplus and lower union utility compared to industry-wide unions. ${ }^{10}$ In what follows the increase in producers surplus and consumers surplus outweighs the loss in

\footnotetext{
9 Straightforward calculations show that $\widehat{w}_{k}^{d}-w^{c}=-\frac{\gamma(a-c)}{2(4-\gamma)}<0$ when both firms refrain from innovation and $\bar{w}_{k}^{d}-w^{c}=-\frac{\gamma(a-c)}{2(2+\gamma)}<0$ when both firms invest in innovation.

${ }^{10}$ We find that $\widehat{P S}^{d}-\widehat{P S}^{C}=\frac{\gamma(a-c)^{2}(8-\gamma)}{2(4-\gamma)^{2}(2+\gamma)^{2}}>0, \overline{C S}^{d}-\overline{C S}^{c}=\frac{\gamma(a-c)^{2}(1+3 \gamma)(4+3 \gamma)}{8(2+\gamma)^{2}(1+2 \gamma)^{2}}>0, \widehat{U}^{d}-\widehat{U}^{C}=$ $-\frac{\gamma^{2}(a-c)^{2}}{2(4-\gamma)^{2}(2+\gamma)}<0$ when no firms innovate and $\overline{P S}^{d}-\overline{P S}^{c}=\frac{\gamma(a-c)^{2}(1+\gamma)(4+3 \gamma)}{4(2+\gamma)^{2}(1+2 \gamma)^{2}}>0, \widehat{C S}^{d}-\widehat{C S}^{C}=$ $\frac{\gamma(a-c)^{2}(8-\gamma)(1+\gamma)}{4(4-\gamma)^{2}(2+\gamma)^{2}}>0, \bar{U}^{d}-\bar{U}^{c}=-\frac{\gamma^{2}(a-c)^{2}}{2(2+\gamma)^{2}(1+2 \gamma)}<0$ when both firms innovate.
} 
union utility, thus resulting in a overall higher welfare under the former union structure than the latter.

\section{The implications of asymmetric product differentiation}

Considering symmetric product differentiatio, we have shown in Section 2 that the incentive for product innovation is higher under decentralised unions. While symmetric product differentiation is certainly a useful starting point for the analysis, there is no reason to believe that the products cannot be differentiated asymmetrically. In a more general framework, one should use different parameters to capture the degrees of product differentiation between $g, h, y$ and $z$. However, to make our discussions analytically tractable, we consider in this section, a particular type of asymmetric product differentiation to show that the results of Section 2 are sensitive to the assumption of symmetric product differentiation. We show that the incentive for product innovation may be higher under a centralised union if the products are asymmetrically differentiated.

The model specific assumptions made in Section 2 also hold in this section with the exception that we consider the existing products of the firms, i.e., $g$ and $h$, are perfectly substitutable. To economise on notations let's define the existing products as product $x$. This modification gives us the inverse market demand functions for $x, y$ and $z$, respectively, as:

$$
\begin{aligned}
& P_{x}=a-q_{x}-\gamma q_{y}-\gamma q_{z} \\
& P_{y}=a-q_{y}-\gamma q_{x}-\gamma q_{z} \\
& P_{z}=a-q_{z}-\gamma q_{x}-\gamma q_{y}
\end{aligned}
$$

We consider the game structure similar to Section 2. 


\subsection{The equilibrium outputs}

If there is no innovation by any firm, only product $x$ will be produced, and the inverse demand function becomes $P_{x}=a-q_{x}$. Given the wages $w_{1}$ and $w_{2}$ for firm 1 and 2 respectively, the equilibrium outputs of firm 1 and firm 2 yield:

$$
\begin{aligned}
& \hat{q}_{x_{1}}^{\rho}=\frac{1}{3}\left(a-2 w_{1}^{\rho}+w_{2}^{\rho}\right) \\
& \hat{q}_{x_{2}}^{\rho}=\frac{1}{3}\left(a+w_{1}^{\rho}-2 w_{2}^{\rho}\right)
\end{aligned}
$$

Now, consider the situation where only firm 1 innovates a new product and firm 2 does not innovate. This corresponds to $q_{z}=0$. Straightforward calculations show that the equilibrium outputs of firms 1 and 2 are respectively:

$$
\begin{aligned}
& \tilde{q}_{x_{1}}^{\rho}=\frac{a(2-\gamma)-(4+\gamma) w_{1}^{\rho}+2(1+\gamma) w_{2}^{\rho}}{6(1+\gamma)} \\
& \tilde{q}_{x_{2}}^{\rho}=\frac{1}{3}\left(a+w_{1}^{\rho}-2 w_{2}^{\rho}\right) \\
& \tilde{q}_{y}^{\rho}=\frac{1}{2}\left(\frac{a-w_{1}^{\rho}}{1+\gamma}\right) .
\end{aligned}
$$

If only firm 2 innovates, it implies that $q_{y}=0$. In this situation, we get the equilibrium outputs as:

$$
\begin{aligned}
& \tilde{q}_{x_{1}}^{\rho}=\frac{1}{3}\left(a-2 w_{1}^{\rho}+w_{2}^{\rho}\right) \\
& \tilde{q}_{x_{2}}^{\rho}=\frac{a(2-\gamma)+2(1+\gamma) w_{1}^{\rho}-(4+\gamma) w_{2}^{\rho}}{6(1+\gamma)} \\
& \tilde{q}_{z}^{\rho}=\frac{1}{2}\left(\frac{a-w_{2}^{\rho}}{1+\gamma}\right) .
\end{aligned}
$$

Finally, consider the case where both firms innovate. In this situation, the equilibrium outputs give: 


$$
\begin{aligned}
& \bar{q}_{x_{1}}^{\rho}=\frac{2}{3}\left(\frac{a(2+\gamma)-(4+5 \gamma) w_{1}^{\rho}+2(1+2 \gamma) w_{2}^{\rho}}{(2+3 \gamma)(2+\gamma)}\right) \\
& \bar{q}_{x_{2}}^{\rho}=\frac{2}{3}\left(\frac{a(2+\gamma)+2(1+2 \gamma) w_{1}^{\rho}-(4+5 \gamma) w_{2}^{\rho}}{(2+3 \gamma)(2+\gamma)}\right) \\
& \bar{q}_{y}^{\rho}=\frac{a(2+\gamma)-2(1+\gamma) w_{1}^{\rho}+\gamma w_{2}^{\rho}}{(2+3 \gamma)(2+\gamma)} \\
& \bar{q}_{z}^{\rho}=\frac{a(2+\gamma)+\gamma w_{1}^{\rho}-2(1+\gamma) w_{2}^{\rho}}{(2+3 \gamma)(2+\gamma)} .
\end{aligned}
$$

\subsection{Wages and profits}

In this section, we solve the wage setting game similar to Section 2. We begin our analysis with centralised union and investigate the firms' innovation incentives under such union structure. We repeat the same exercise under decentralised unions, in the subsequent section.

\subsubsection{A centralised union}

Similar to the case of symmetric product differentiation, we get the equilibrium wage as $w^{c}=\frac{1}{2}(a+c)$, irrespective of the innovation strategies adopted by the firms and regardless of whether the labour union charges a uniform wage or discriminatory wages.

Next, we discuss the innovation game where we can construct a pay-off table identical to Table 1. To avoid analytical repetition, we only report the closed form solutions of firms' profits in Table B.1 in Appendix B. The appended equilibrium profit levels in Table B.1 allow us to derive an investment ranking analogous to Proposition 1 which we report below. 
Proposition 4: Assume that the labour union is centralised in nature.

(a) Both firms innovate if $I<I_{l}^{c}$,

(b) Neither firm innovates if $I_{h}^{c}<I$,

(c) Only one firm innovates if $I_{l}^{c}<I<I_{h}^{c}$

where, $I_{l}^{c}=\frac{1}{4}\left(1-\gamma^{2}\right)\left(\frac{a-c}{2+3 \gamma}\right)^{2}$ and, $I_{h}^{c}=\frac{1}{16}\left(\frac{1-\gamma}{1+\gamma}\right)(a-c)^{2}$.

Proof: Check that $I_{l}^{c}-I_{h}^{c}=-\frac{\gamma(a-c)^{2}(1-\gamma)(4+5 \gamma)}{16(1+\gamma)(2+3 \gamma)^{2}}<0$.

The intuition of the above proposition is similar to that of Proposition 1.

\subsubsection{Decentralised unions}

Now consider the case of decentralised unions. If neither firm innovates, the equilibrium wages of firms 1 and 2 ex-post R\&D can be found as:

$$
\hat{w}_{1}^{d}=\hat{w}_{2}^{d}=\frac{1}{3}(a+2 c) \text {. }
$$

Next, we consider the case where only one firm innovates. The equilibrium wages of the innovating and non-innovating firm ex-post R\&D are given by:

$$
\begin{aligned}
& \tilde{w}_{i v}^{d}=\frac{a(11-\gamma)+4 c(4+\gamma)}{3(9+\gamma)} \\
& \tilde{w}_{n v}^{d}=\frac{a(19+\gamma)+5 c(7+\gamma)}{6(9+\gamma)}
\end{aligned}
$$

Finally, consider the case where both firms innovate. In this situation, the equilibrium wages ex-post R\&D are: 


$$
\bar{w}_{1}^{d}=\bar{w}_{2}^{d}=\frac{5 a(2+\gamma)+2 c(7+8 \gamma)}{3(8+7 \gamma)} .
$$

Upon inspection we get the following Lemma.

Lemma 3: Assume that the labour unions are decentralised in nature. We get the following wage rankings:

(a) Compared to the case of no innovation, innovation reduces the wage paid by the innovating firm when both firms innovate.

(b) Compared to the case of no innovation, innovation increases the wage paid by the innovating firm when only one firm innovates, i.e., $\tilde{w}_{i v}^{d}-\hat{w}_{k}^{d}>0$.

Proof: See that $\bar{w}_{k}^{d}-\hat{w}_{k}^{d}=-\frac{2(a-c)(1-\gamma)}{3(8+7 \gamma)}<0 \quad$ and $\quad \tilde{w}_{i v}^{d}-\hat{w}_{k}^{d}=\frac{(a-c)(1-\gamma)}{3(9+\gamma)}>0$.

While the intuitions for Lemma 1 also remain for the first part of Lemma 3, we find that the innovating firm pays a higher labour cost when only one firm invests in R\&D. The reason is that when the products are asymmetrically differentiated the innovation by only one firm increases its own market share significantly compared to its non-innovating rival. The labour unions, in turn, also increase the wage pressure on the innovating firm by a substantial amount. The first effect being not so strong, the innovating firm pays a higher equilibrium wage when its rival firm refrains from innovating new products.

Given the equilibrium wages prescribed above we can produce a pay-off matrix of the firms analogous to Table 2. We report the closed form solutions of the equilibrium profits in Table B.2 in Appendix B. 
Proposition 5: Assume that the unions are decentralised in nature.

(a) If $0<\gamma<0.04$ (i) both firms innovate if $I<I_{l}^{d}$, and neither firm innovates for $I_{l}^{d}<I$

(b) If $0.07<\gamma<1$ (i) both firms innovate if $I<I_{l}^{d}$, (ii) neither firm innovates if $I_{h}^{d}<I$, and (iii) only one firm innovates if $I_{l}^{d}<I<I_{h}^{d}$,

where, $\quad I_{l}^{d}=(a-c)^{2}\left(\frac{4(13+12 \gamma)(7+8 \gamma)^{2}}{81(2+3 \gamma)^{2}(8+7 \gamma)^{2}}-\frac{5(7+\gamma)(19+\gamma)}{162(9+\gamma)^{2}}\right) \quad$ and $I_{h}^{d}=\frac{4}{81}(a-c)^{2}\left(\frac{(4+\gamma)(7+\gamma)(7-2 \gamma)}{(1+\gamma)(9+\gamma)^{2}}-1\right)$

Proof: Check that $I_{l}^{d}-I_{h}^{d}=-\frac{(a-c)^{2}(1-\gamma)\left(135104 \gamma+536108 \gamma^{2}+719308 \gamma^{3}+422853 \gamma^{4}+105264 \gamma^{5}+8379 \gamma^{6}-7016\right)}{162(1+\gamma)(9+\gamma)^{2}(2+3 \gamma)^{2}(8+7 \gamma)^{2}}$

We find that (RD, RD) is the equilibrium strategy for $I<I_{l}^{d}$ and (No RD, No RD) is the equilibrium strategy for $I>I_{h}^{d}$. We also get that $I_{l}^{d}<I_{h}^{d}$ for $0<\gamma<0.04$. Hence, it is immediate that both firms innovate when $I<I_{h}^{d}$ and neither firm innovates when $I_{l}^{d}<I$. If $I \in\left(I_{h}^{d}, I_{l}^{d}\right)$, we get two pure strategy equilibria: both firms innovate (RD, RD) and neither firm innovates (No RD, No RD). We also find that each firm earns higher profit in the former equilibrium than in the latter. Hence, following the focal point argument (Schelling, 1960), we argue that higher profit in the former equilibrium acts as a focal point and induces both firms to innovate. Therefore, it follows that both firms innovate for $I<I_{l}^{d}$ and neither firm innovates for $I_{l}^{d}<I$ if $0<\gamma<0.04$. 
However, for $0.04<\gamma<1$ we get that $I_{l}^{d}<I_{h}^{d}$. Hence, the second part of the proposition is immediate.

The intuition for the above result is similar to Proposition 2 with the exception that, in the presence of asymmetric product differentiation, the wage effects create higher strategic incentive for innovation when the degree of product differentiation is sufficiently low, i.e., $\quad \gamma<0.04$.

\subsection{The effects of unionisation structure on innovation}

We are now in a position to show the effects of the unionisation structures on innovation. Comparing the critical values mentioned in Propositions 4 and 5 , we get the following investment orderings:

$$
\begin{array}{ll}
I_{l}^{c}<I_{h}^{c}<I_{h}^{d}<I_{l}^{d} & \text { for } 0<\gamma<0.04 \\
I_{l}^{c}<I_{h}^{c}<I_{l}^{d}<I_{h}^{d} & \text { for } 0.04 \leq \gamma<0.35 \\
I_{l}^{c}<I_{l}^{d}<I_{h}^{d}<I_{h}^{c} & \text { for } 0.35 \leq \gamma<1
\end{array}
$$

We discuss the results in the following proposition.

Proposition 6: (a) If $0<\gamma<0.35$ the incentive for innovation is higher under decentralised labour unions compared to a centralised labour union irrespective of whether both firms innovate or only one firm innovates.

(b) If $0.35 \leq \gamma<1$, the incentive for innovation is higher under a centralised labour union when only one firm innovates whereas it is higher under decentralised unions when both firms innovate.

The above results suggest that the overall incentives for innovation under the respective union structures depend on the degree of product differentiation between the existing products and the new products. Straightforward calculations show that due the monopoly nature of the centralised union, it always charges a higher wage compared to 
decentralised unions irrespective of the product differentiation, regardless of the innovation strategies adopted by the firms. The output effect and hence, the impact on firms' profits, on the other hand, varies with the degree of product differentiation. If the products are sufficiently differentiated i.e., $0<\gamma<0.35$, meaning that if the existing products and the new products are almost isolated, the new products do not have significant effects on the market shares of the existing products. In this situation, the wage effect dominates the output effect and the overall innovation incentive becomes lower under a centralised union than the decentralised unions.

Next, consider the case where $0.35 \leq \gamma<1$. The above proposition shows that the incentive for innovation is higher under a centralised union when only one firm innovates (i.e., $I_{h}^{d}<I_{h}^{c}$ ) whereas it is higher under decentralised unions when both firms innovate (i.e., $I_{l}^{c}<I_{l}^{d}$ ). We explain these results in terms of non-strategic benefit for innovation $\left(I_{h}^{\rho}\right)$ and strategic benefit for innovation $\left(I_{l}^{\rho}\right)$ respectively (see Proposition 1 for definitions). We begin with firm 1's non-strategic benefit for innovation where $I_{h}^{\rho} \leq \hat{\pi}_{1}^{\rho}[g ; h]-\tilde{\pi}_{1}^{\rho}[(g, y) ; h]$. Note that, under both unionised structures firm 1 's profits under no innovation i.e., $\hat{\pi}_{1}^{c}[g ; h]$ and $\hat{\pi}_{1}^{d}[g ; h]$ are independent of $\gamma$ (see Table B.1 and B.2 in Appendix B). This means that a change in product differentiation leaves these profits unaffected. However, a fall in product differentiation reduces firm 1 's total profit when it undertakes $R \& D$ given that its rival (firm 2) does not invest in innovation. These profit losses occur under both unionisation structures. ${ }^{11}$ Since a lower wage pressure under decentralised unions generate higher outputs under such union structure compared to a centralised union, the loss in profits

11 Check that $\frac{\partial \tilde{\pi}_{1}^{c}[(g, y) ; h]}{\partial \gamma}=-\frac{(a-c)^{2}}{8(1+\gamma)^{2}}<0 \& \frac{\partial \tilde{\pi}_{1}^{d}[(g, y) ; h]}{\partial \gamma}=-\frac{(a-c)^{2}\left(1967+879 \gamma+231 \gamma^{2}+23 \gamma^{3}\right)}{2(1+\gamma)^{2}(9+\gamma)^{3}}<0$ 
due to lower product differentiation is also higher under the former structure than the latter. Hence, if the reduction in product differentiation is large, firm 1 invests more under a centralised union compared to decentralised unions. As the firms are symmetric in nature, similar argument holds for firm 2.

Let us now consider firm 1's strategic benefit for innovation where $I_{l}^{\rho} \leq \bar{\pi}_{1}^{\rho}[(g, y) ;(h, z)]-\tilde{\pi}_{1}^{\rho}[g ;(h, z)]$. Given that firm 2 invests in innovation, a lower product differentiation leaves firm 1's profit under centralised union, i.e., $\hat{\pi}_{1}^{c}[g ;(h, z)]$ unaltered as it does not depend on the product differentiation parameter, $\gamma$. However, it reduces the profits of firm 1 under decentralised union when it does not innovate, as well as its profits under both unionised structures when it innovates. ${ }^{12}$ In what follows, the wage demand being higher under the centralised union, the loss in profit under the centralised union when firm 1 innovates dominates the loss in its profit under decentralised unions. Therefore, the strategic benefit being higher under the decentralised unions, the firm 1 (and firm 2 by similar argument) invests more under such union structures compared to an industry-wide union.

\subsection{Welfare analysis}

We now return to the discussion of welfare implications under the respective union structures. Similar to Section 2, we derive the welfare ranking as below. To avoid analytical repetition we only report the overall welfare comparison under the respective union structures.

\footnotetext{
${ }^{12}$ See that

$\frac{\partial \tilde{\pi}_{1}^{d}[g ;(h, z)]}{\partial \gamma}=-\frac{(a-c)^{2}\left(416+27616 \gamma+77256 \gamma^{2}+74601 \gamma^{3}+24486 \gamma^{4}\right)}{54(2+3 \gamma)^{3}(8+7 \gamma)^{3}}<0, \frac{\partial \bar{\pi}_{1}^{c}[(g, y) ;(h, z)]}{\partial \gamma}=-\frac{(a-c)^{2}(3+2 \gamma)}{2(2+3 \gamma)^{3}}<0$ and $\frac{\partial \bar{\pi}_{1}^{d}[(g, y) ;(h, z)]}{\partial \gamma}=-\frac{16(a-c)^{2}(7+8 \gamma)\left(187+519 \gamma+501 \gamma^{2}+168 \gamma^{3}\right)}{27(2+3 \gamma)^{3}(8+7 \gamma)^{3}}<0$.
} 
Lemma 4: Decentralised unions yield higher social welfare compared to a centralised union regardless of whether no firm innovates or both firms innovate.

Proof: See that $\widehat{S W}_{k}^{d}-\widehat{S W}_{k}^{c}=\frac{4(a-c)^{2}(6+\gamma)}{81}-\frac{(a-c)^{2}(9+\gamma)}{36}=\frac{(a-c)^{2}(15+7 \gamma)}{324}>0$ and $\quad \overline{S W}_{k}^{d}-\overline{S W}_{k}^{c}=\frac{4(a-c)^{2}(7+8 \gamma)\left(573+1598 \gamma+1009 \gamma^{2}\right)}{81(2+3 \gamma)^{2}(8+7 \gamma)^{2}}-\frac{(a-c)^{2}(99+151 \gamma)}{36(2+3 \gamma)^{2}}=$ $\frac{(a-c)^{2}\left(7152+65552 \gamma+121685 \gamma^{2}-625618 \gamma^{3}\right)}{324(2+3 \gamma)^{2}(8+7 \gamma)^{2}}>0$.

The intuitions of the above lemma are in line with Lemma 2.

\section{Conclusion}

This paper explains how unionisation structures, viz., centralised and decentralised labour unions, affect the incentive for product innovation. While few recent papers studied the effects of different unionisation structures on process innovation, our paper provides a new perspective to the literature by focusing on new product development. While process innovation is an important aspect of $R \& D$, empirical observations suggest that the firms allocate a significant amount of their budget towards product $R \& D$. We take up this issue in our paper and investigate how the type and degree of product differentiation affect the incentives for product innovation in a unionised labour market. We show that if the products are symmetrically differentiated, the incentive for innovation is higher under decentralised labour unions compared to a centralised labour union. However, considering a particular type of asymmetric product differentiation, we show that the incentive for innovation may be higher under a centralised labour union than decentralised unions.

While the novelty of this paper lies in new product development and how the incentive for innovating a brand new product is influenced by different union structures, viz., centralised and decentralised unions, it would be equally intriguing to investigate how the results would differ if the products are differentiated vertically, if 
the firms compete in prices or act as a market leader, if the innovating firms invest both in product and process $\mathrm{R} \& \mathrm{D}$, if the wage and employment negotiation between labour unions and firms take the form of efficient bargaining. As each of these questions would require a thorough analysis, we leave them for future work. 


\section{Appendix}

Appendix A: The case of symmetric product differentiation

Table A.1: Firms' payoffs under a Centralised Union

\begin{tabular}{|c|c|}
\hline Neither firm innovates & $\hat{\pi}_{1}^{c}[g ; h]=\hat{\pi}_{2}^{c}[g ; h]=\frac{1}{4}\left(\frac{a-c}{2+\gamma}\right)^{2}$ \\
\hline One firm innovates & $\begin{array}{l}\tilde{\pi}_{1}^{c}[(g, y) ; h]=\tilde{\pi}_{2}^{c}[g ;(h, z)]=\frac{(a-c)^{2}(1+\gamma)(2-\gamma)^{2}}{8\left(2+2 \gamma-\gamma^{2}\right)^{2}}-I \\
\end{array}$ \\
\hline Both firms innovate & $\tilde{\pi}_{1}^{c}[g ;(h, z)]=\tilde{\pi}_{2}^{c}[(g, y) ; h]=\frac{(a-c)^{2}}{4\left(2+2 \gamma-\gamma^{2}\right)^{2}}$ \\
& $\bar{\pi}_{1}^{c}[(g, y) ;(h, z)]=\bar{\pi}_{2}^{c}[(g, y) ;(h, z)]=\frac{(a-c)^{2}(1+\gamma)}{8(1+2 \gamma)^{2}}-I$ \\
\hline
\end{tabular}

Table A.2: Firms' payoffs under Decentralised Union

\begin{tabular}{|c|c|}
\hline $\begin{array}{c}\text { Neither firm } \\
\text { innovates }\end{array}$ & $\hat{\pi}_{1}^{d}[g ; h]=\hat{\pi}_{2}^{d}[g ; h]=\frac{4(a-c)^{2}}{(2+\gamma)^{2}(4-\gamma)^{2}}$ \\
\hline One firm & $\tilde{\pi}_{1}^{d}[(g, y) ; h]=\tilde{\pi}_{2}^{d}[g ;(h, z)]=\frac{2(a-c)^{2}(1+\gamma)\left(4+3 \gamma-2 \gamma^{2}\right)^{2}}{\left(2+2 \gamma-\gamma^{2}\right)^{2}\left(8+8 \gamma-\gamma^{2}\right)^{2}}-I$ \\
innovates & $\tilde{\pi}_{1}^{d}[g ;(h, z)]=\tilde{\pi}_{2}^{d}[(g, y) ; h]=\frac{(a-c)^{2}(1+\gamma)^{2}\left(4+2 \gamma-\gamma^{2}\right)^{2}}{\left(2+2 \gamma-\gamma^{2}\right)^{2}\left(8+8 \gamma-\gamma^{2}\right)^{2}}$ \\
\hline Both firms & $\bar{\pi}_{1}^{d}[(g, y) ;(h, z)]=\bar{\pi}_{2}^{d}[(g, y) ;(h, z)]=\frac{(a-c)^{2}(1+\gamma)^{3}}{2(2+\gamma)^{2}(1+2 \gamma)^{2}}-I$ \\
\hline innovate &
\end{tabular}


Appendix B: The case of asymmetric product differentiation

Table B.1: Firms' payoffs under a Centralised Union

\begin{tabular}{|c|c|}
\hline $\begin{array}{c}\text { Neither firm } \\
\text { innovates }\end{array}$ & $\hat{\pi}_{1}^{c}[g ; h]=\hat{\pi}_{2}^{c}[g ; h]=\left(\frac{a-c}{6}\right)^{2}$ \\
\hline \multirow{2}{*}{ One firm innovates } & $\tilde{\pi}_{1}^{c}[(g, y) ; h]=\tilde{\pi}_{2}^{c}[g ;(h, z)]=\frac{(a-c)^{2}(13-5 \gamma)}{144(1+\gamma)}-I$ \\
& $\tilde{\pi}_{1}^{c}[g ;(h, z)]=\tilde{\pi}_{2}^{c}[(g, y) ; h]=\left(\frac{a-c}{6}\right)^{2}$ \\
\hline Both firms innovate & $\bar{\pi}_{1}^{c}[(g, y) ;(h, z)]=\bar{\pi}_{2}^{c}[(g, y) ;(h, z)]=\frac{(a-c)^{2}(13+12 \gamma)}{36(2+3 \gamma)^{2}}-I$ \\
\hline
\end{tabular}

Table B.2: Firms' payoffs under Decentralised Union

\begin{tabular}{|c|c|}
\hline $\begin{array}{c}\text { Neither } \\
\text { firm }\end{array}$ & $\hat{\pi}_{1}^{d}[g ; h]=\hat{\pi}_{2}^{d}[g ; h]=\frac{4(a-c)^{2}}{81}$ \\
innovates & $\tilde{\pi}_{1}^{d}[(g, y) ; h]=\tilde{\pi}_{2}^{d}[g ;(h, z)]=\frac{4(a-c)^{2}(4+\gamma)(7+\gamma)(7-2 \gamma)}{8(1+\gamma)(9+\gamma)^{2}}-I$ \\
\hline One firm & $\tilde{\pi}_{1}^{d}[g ;(h, z)]=\tilde{\pi}_{2}^{d}[(g, y) ; h]=\frac{5(a-c)^{2}(7+\gamma)(19+\gamma)}{162(9+\gamma)^{2}}$ \\
innovates & $\bar{\pi}_{1}^{d}[(g, y) ;(h, z)]=\bar{\pi}_{2}^{d}[(g, y) ;(h, z)]=\frac{4(a-c)^{2}(7+8 \gamma)^{2}(13+12 \gamma)}{81(2+3 \gamma)^{2}(8+7 \gamma)^{2}}-I$ \\
\hline Both firms & \\
\hline
\end{tabular}




\section{References}

Addison, J. T. and J. Wagner, 1994, 'UK unionism and innovative activity: some cautionary remarks on the basis of a simple cross-country test', British Journal of Industrial Relations, 32: 83-98.

Bassanini, A. and E. Ernst, 2002, 'Labour market institutions, product market regulation, and innovation: cross country evidence', OECD Economics Department Working Paper, 316, Paris.

Braun, S., 2008, 'Economic integration, process and product innovation, and relative skill demand', Review of International Economics, 16: 864-873.

Bronas, S. G. and D. R. Deere, 1993, 'Unionisation, incomplete contracting, and capital investment', Journal of Business, 66: 117-32.

Bughin, J and S. Vannini, 1995, 'Strategic direct investment under unionised oligopoly', International Journal of Industrial organisation, 13: 127-45.

Calabuig, V. and M. Gonzalez-Maestre, 2002, 'Union structure and incentives for innovation', European Journal of Political Economy, 18, 177-92.

Calmfors, L. and J. Drifill, 1988, 'Centralisation and wage bargaining', Economic Policy, 6: 13-61.

Chu, A.C., G. Cozzi, and Y. Furukawa, 2016, 'Unions, innovation and cross-country wage inequality', Journal of Economic Dynamics and Control, 64: 104-118.

Davidson, C., 1988, 'Multiunit Bargaining in oligopolistic industries', Journal of labour Economics 6, 397-422.

Dhillon, A. and E. Petrakis, 2002, 'A generalized wage rigidity result', International Journal of Industrial Organisation, 20: 285-311.

Dobson, P. W., 1994, 'Multifirm unions and the incentive to adopt pattern bargaining in oligopoly', European Economic Review, 38: 87-100.

Flanagan, R. J., 1999, 'Macroeconomic performance and collective bargaining: an 
international perspective', Journal of Economic Literature, 37: 1150-75.

Freeman, R. and J. Medoff, 1984, What do unions do?, Basic Books, New York.

Grout, P. A., 1984, 'Investment and wages in the absence of binding contracts: a Nash bargaining approach', Econometrica, 52: 449-60.

Haucap, J. and C. Wey, 2004, 'Unionisation structures and innovation incentives', Economic Journal 114: C149-65.

Hirsch, B.T., 2004, 'What do unions do for economic performances?', Journal of labour Research, 25: 415-55.

Horn, H. and A. Wolinsky, 1988, 'Bilateral monopolies and incentive for merger', Rand Journal of Economics 19, 408-19.

Imai, K., 1992, 'The Japanese pattern of innovation and its evolution', in N. Rosenberg, R. Laudan and D. Mowery (Eds.), Technology and the wealth of nations, Stanford University Press, Stanford.

Iversen, T., 1998, 'Wage bargaining, central bank independence and the real effects of money', International Organisation, 52: 469-504.

Katz, H. C., 1993, 'The decentralization of collective bargaining: a literature review and comparative analysis', Industrial and Labour Relations Review, 47: 3-22.

Lambertini, L. and A. Mantovani, 2009, 'Process and product innovation by a multiproduct monopolist: a dynamic approach', International Journal of Industrial Organisation, 27: 508-18.

Lambertini, L. and A. Mantovani, 2010, 'Process and product innovation: a differential game approach to product life cycle', International Journal of Economic Theory, 6: $227-52$.

Layard, R., S. Nickell and R. Jackman, 1991, Unemployment, macroeconomic performance and the labour market, Oxford University Press, Oxford.

Leahy, D. and C. Montagna, 2000, 'Unionisation and foreign direct investment: 
challenging conventional wisdom?', Economic Journal, 110: C80-92.

Lin, P. and K. Saggi, 2002, 'Product differentiation, process R\&D, and the nature of market competition', European Economic Review, 46: 201-11.

López, M. C. and R. A. Naylor, 2004, 'The Cournot-Bertrand profit differential: a reversal result in a differentiated duopoly with wage bargaining', European Economic Review, 48: 681-96.

Manasakis, C. and E. Petrakis, 2009, 'Union structure and firms' incentives for cooperative R\&D investments', Canadian Journal of Economics, 42: 665-93.

Mansfield, E., 1988, 'Industrial R\&D in Japan and the United States: a comparative study', American Economic Review, 78: 223-28.

Menezes-Filho, N. and J. Van Reenen, 2003, 'Unions and innovation: a survey of the theory and empirical evidence', CEPR Discussion Paper, No. 3792.

Menezes-Filho, N., D. Ulph and J. Van Reenen, 1998, 'The determination of R\&D: empirical evidence on the rule of unions', European economic Review, 42: 919-30.

Moene, K. O. and M. Wallerstein, 1997, 'Pay inequality', Journal of Labour Economics, 15: 403-30.

Mukherjee, A. and E. Pennings, 2004, 'Imitation, patent protection and welfare', Oxford Economic Papers, 56: 715-33.

Mukherjee, A. and E. Pennings, 2011, 'Unionisation structure, licensing and innovation', International Journal of Industrial Organisation, 29: 232-41.

Mukherjee, A. and U. B. Sinha, 2012, 'Patent Protection, Southern Innovation and Welfare in a North-South Trade Mode', Economica, 80: 248-73.

Nickell, S., 1997, 'Unemployment and labour market rigidities: Europe versus North America', Journal of Economic Perspectives, 11: 55-74.

OECD, 1996, The OECD jobs study: implementing the strategy, OECD, Paris. 
OECD, 2004, Trade and migration: building bridges for global labour mobility, OECD, Paris.

Oswald, A. J., 1993, 'Efficient contracts are on the labour demand curve: theory and facts', Labour Economics, 1: 85-113.

Palokangas, T., 1996, 'Endogenous growth and collective bargaining', Journal of Economic Dynamics and Control, 20: 925-944.

Palokangas, T., 2004, 'Union-firm bargaining, productivity improvement and endogenous growth', Labour, 18: 191-205.

Rosenkranz, S., 2003, 'Simultaneous choice of process and product innovation when consumers have a preference for product variety', Journal of Economic Behavior \& Organisation, 50: 183-201.

Roy Chowdhury, P., 2005, 'Patents and R\&D: the tournament effect', Economics Letters, 89: 120-26.

Siebert, H., 1997, 'Labour market rigidities: at the root of unemployment in Europe', Journal of Economic Perspectives, 11: 37-54.

Symeonidis, G., 2003, 'Comparing Cournot and Bertrand equilibria in a differentiated duopoly with product R\&D', International Journal of Industrial Organization, 21: $39-55$.

Tauman, Y. and Y. Weiss, 1987, 'Labour unions and the adoption of new technology', Journal of labour Economics, 5: 477-501.

Ulph, A., 1989, 'The incentives to make commitments in wage bargains', Review of Economic Studies, 56: 449-66.

Ulph, A. and D. Ulph, 1989, 'Labour markets and innovation', Journal of Japanese and International Economics, 3: 403-23.

Ulph, A. and D. Ulph, 1994, 'Labour markets, bargaining and innovation', European Economic Review, 42: 931-39. 
Ulph, A. and D. Ulph, 2001, 'Strategic innovation with complete and incomplete labour market contracts', Scandinavian Journal of Economics, 103: 265-82.

Ulph, A. and D. Ulph, 1998, 'Labour markets, bargaining and innovation', European Economic Review, 42: 931-39.

Van der Ploeg, F., 1987, 'Trade unions, investment, and employment', European Economic Review, 31: 1465-92.

Vannini, S. and J. Bughin, 2000, 'To be (unionised) or not to be? a case for cost-raising strategies under Cournot oligopoly', European Economic Review, 44: 1763-81.

Wallerstein, M., 1999, 'Wage-setting institutions and pay inequality in advanced industrial societies', American Journal of Political Science, 43: 649-80. 